\title{
Prescription Patterns in Patients with Chronic Obstructive Pulmonary Disease and Osteoporosis
}

This article was published in the following Dove Press journal:

International Journal of Chronic Obstructive Pulmonary Disease

\author{
Kuang-Ming Liao $\mathbb{I D}^{\prime}$ \\ Kai-Lin Chiu ${ }^{2,3}$ \\ Chung-Yu Chen $\mathbb{D}^{2-5}$ \\ 'Department of Internal Medicine, Chi \\ Mei Medical Center, Chiali, Taiwan, \\ Republic of China; ${ }^{2}$ Master Program in \\ Clinical Pharmacy, School of Pharmacy, \\ Kaohsiung Medical University, Kaohsiung, \\ Taiwan, Republic of China; ${ }^{3}$ Department \\ of Pharmacy, Kaohsiung Medical \\ University Hospital, Kaohsiung, Taiwan, \\ Republic of China; ${ }^{4}$ Department of \\ Medical Research, Kaohsiung Medical \\ University Hospital, Kaohsiung, Taiwan, \\ Republic of China; ${ }^{5}$ Center for Big Data \\ Research, Kaohsiung Medical University, \\ Kaohsiung, Taiwan
}

Correspondence: Chung-Yu Chen Kaohsiung Medical University, No. 100, Shiquan Ist Road, Sanmin District, Kaohsiung, 807, Taiwan, Republic of China Email jk2975525@kmu.edu.tw

\begin{abstract}
Objective: Patients with chronic obstructive pulmonary disease (COPD) have a higher risk of osteoporosis. Few studies have addressed the prescription patterns in osteoporosis patients with COPD. The purpose of this study was to conduct a retrospective study of the prescription patterns in patients with COPD and osteoporosis in Taiwan.

Methods: The study was conducted with data from the Taiwan National Health Insurance Research Database from January 1, 2003, to December 31, 2016. We selected the COPD population in Taiwan older than 40 years with at least one prescription for a bronchodilator. We excluded patients who had osteoporosis, fracture, asthma, or cancer before the diagnosis of COPD. After the diagnosis of COPD, patients who did not have osteoporosis were also excluded. We followed this COPD and osteoporosis cohort until they had been prescribed medication for osteoporosis.
\end{abstract}

Results: There were 13,407 patients with COPD and osteoporosis who received osteoporosis treatment. Among the patients who received treatment, the majority were female $(\mathrm{n}=$ 9136), accounting for $68.14 \%$ of all treated patients. A total of $53.4 \%$ of the patients had been prescribed steroids least once within the last year before receiving a diagnosis of osteoporosis. A total of $34.61 \%$ of the patients received systemic corticosteroids with a daily dose equivalent to $5 \mathrm{mg}$ of prednisolone within the 3 months prior to the diagnosis of osteoporosis. The older the patient was, the higher the probability of the prescription of medication for osteoporosis. Patients with depression had a high probability of receiving medication for osteoporosis with adjusted hazard ratio of 1.141 (95\% confidence interval, $1.072-1.214)$.

Conclusion: The rate of prescriptions for the treatment of osteoporosis in patients with COPD was low. Physicians need to be aware of this issue and treat osteoporosis more aggressively in patients with COPD.

Keywords: chronic obstructive pulmonary disease, National Health Insurance Research Database, osteoporosis, prescription pattern

\section{Introduction}

Chronic obstructive pulmonary disease (COPD) is a chronic lung disease with irreversible airway obstruction. COPD is not only a pulmonary disease but also is increasingly recognized as a systemic inflammatory disease. Patients with COPD have extrapulmonary comorbidities, including skeletal muscle diseases and osteoporosis. ${ }^{1,2}$ These comorbidities lead to increased medical expenditures, hospitalization and mortality. ${ }^{3}$ Factors associated with osteoporosis in patients with COPD include old age, a sedentary lifestyle, a low body mass index, smoking, systemic and local inflammation, oxidative stress, corticosteroid use and hormonal 
disturbances. ${ }^{4}$ Compared to the general population, patients with COPD have a two- to five-fold higher risk of osteoporosis. ${ }^{5}$ Fractures due to osteoporosis are indicators of a poor prognosis, and the 1-year mortality rate after hip fractures is higher in COPD patients than in nonCOPD patients. ${ }^{6}$ The early detection and treatment of osteoporosis in patients with COPD reduces the risk of fragility fractures. ${ }^{7}$ Only a few studies have addressed the treatment of osteoporosis in patients with COPD. ${ }^{8-10}$ The purpose of this study was to conduct a retrospective analysis of prescription patterns in patients with COPD and osteoporosis in Taiwan.

\section{Methods}

\section{Study Design and Data Source}

We performed a population-based cohort study of COPD patients with osteoporosis who were 40 years old or older using data from a national database. Taiwan established the National Health Insurance (NHI) program in 1995, and it provides coverage to $99.9 \%$ of the 23 million people living in Taiwan and includes $93.03 \%$ of healthcare providers. The study was conducted with data from the Taiwan National Health Insurance Research Database (NHIRD) from January 1, 2003, to December 31, 2016. The data consisted of all medical claims, pharmacy claims and causes of death. We independently conducted this study at a subcenter of the Health and Welfare Data Science Centers at Kaohsiung Medical University. This study was approved by the Institutional Review Board of the Chi Mei Medical Center (10903-E01), and the database accessed has deidentified data. Researchers must follow the Computer-Processed Personal Data Protection Law and privacy regulations in Taiwan.

\section{Identification of Study Cohort}

The cohort included newly diagnosed COPD patients with more than two outpatient or inpatient visit records from January 1, 2003, to December 31, 2016 (International Classification of Diseases, Ninth Revision [ICD-9] codes 490, 491, 492, 496 and Tenth Revision [ICD-10] codes J40, J41, J43, J44). COPD patients who were 40 years old or older and had outpatient records of using COPD medications within one year after the primary COPD diagnosis date were included. We excluded patients who had osteoporosis, fracture, asthma, or cancer before the diagnosis of COPD. After selecting patients based on the COPD diagnosis, patients who did not have osteoporosis were excluded, and the remaining patients were defined as COPD patients with osteoporosis (ICD-9 codes 733 and ICD-10 codes M80-M82). The cohort entry date was defined as the date of the primary osteoporosis diagnosis. The study cohort was followed until the date of the prescription of drugs to treat osteoporosis, death, NHIRD withdrawal, or the end of this study (December 31, 2017), whichever occurred first.

\section{Measurement of Covariates}

Several covariates were reported as potential confounders of osteoporosis and used as the exclusion criteria, including prior asthma, malignancy, and fracture. Patients who did not develop osteoporosis were also excluded from the analysis of the prescription patterns. COPD severity was determined by proxy indicators, including the number of COPD-related medical records and the use of short-acting beta-agonists (SABAs), antibiotics, or oral corticosteroids. COPD severity was categorized as severe or moderate. Moderate COPD exacerbations were defined based on treatment with systemic corticosteroids and/or antibiotics. Severe exacerbations were defined based on the need for hospitalization or visits to the emergency department.

Other factors related to prescription patterns or osteoporosis were considered. These factors were measured in the year prior to the index date and included alcohol-related disease, cardiovascular disease, chronic kidney disease, liver disease, diabetes, dyslipidemia, hypertension, dementia, depression, Alzheimer's disease, renal failure, and malignancy. We also included these factors in the Cox proportional hazards model for the estimation of the hazard ratio (HR).

\section{Outcome Definition}

The outcome was defined as the prescription of drugs for the treatment of osteoporosis. The drugs prescribed for osteoporosis included bisphosphonate, denosumab, estrogen, raloxifene, human parathyroid hormone (PTH 1-34), and calcitonin. The population with osteoporosis were followed until the date of the prescription of drugs for the treatment of osteoporosis, death, NHIRD withdrawal, or the end of this study (December 31, 2017), whichever occurred first.

\section{Statistical Analysis}

With regard to the baseline characteristics, continuous variables are presented as the means (standard deviations), and categorical variables are presented as percentages. Continuous variables were analyzed with Student's $t$-tests, and categorical variables were analyzed with chi-square tests. 
We used a Cox proportional hazards model to estimate the HR for the prescription of drugs after the diagnosis of osteoporosis. The Cox proportional hazards model was adjusted for demographic characteristics, sex, comorbidities, comedications, and COPD severity. Data processing and statistical analysis were performed with SAS 9.4 software. The statistical significance was determined by a two-tailed $\mathrm{P}$ value $<0.05$.

\section{Results}

There were 29,611 patients with COPD and osteoporosis. There were 13,407 patients who received osteoporosis treatment and 16,204 patients who did not receive treatment. Figure 1 shows the process of patient selection.

Among the patients who received treatment, the majority were female $(n=9136)$, accounting for $68.14 \%$ of all treated patients. The age distribution across age groups with 15-year intervals was as follows: 6.33\% (849) of the patients were $40-54$ years old, $15.92 \%$ (2134) were 55-64 years old, $38.88 \%$ (5213) were $65-74$ years old, and $38.87 \%$ (5211) were 75 years old or older. The common comorbidities ( $>20 \%)$ included hypertension, cardiovascular disease (including coronary artery disease, peripheral

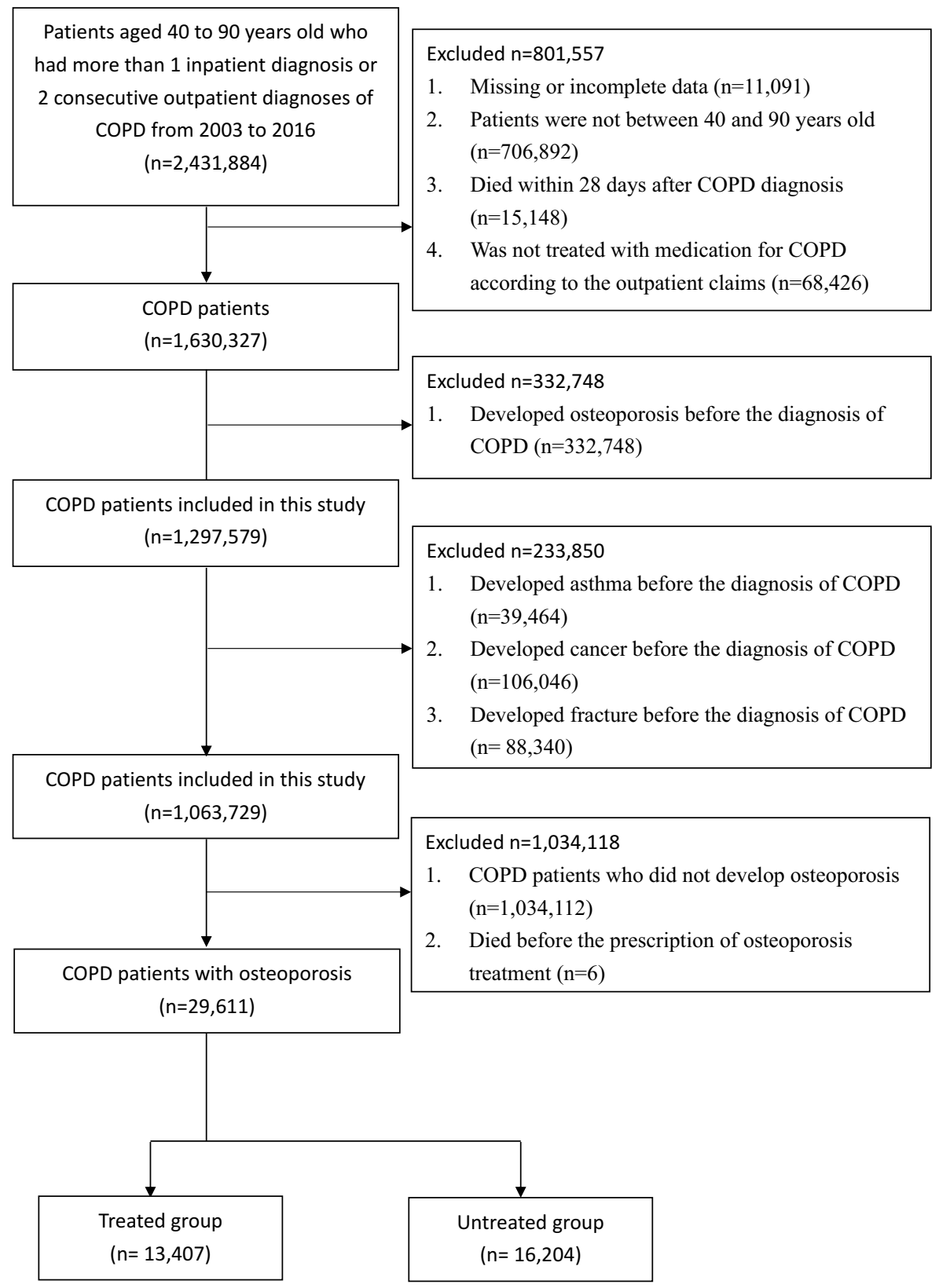

Figure I Flowchart of patient enrolment and final study sample. 
Table I Characteristics of COPD Patients with Osteoporosis Who Were and Were Not Treated

\begin{tabular}{|c|c|c|c|c|c|}
\hline \multirow[t]{2}{*}{ Baseline Characteristics, n (\%) } & \multicolumn{2}{|c|}{ Treated Group } & \multicolumn{2}{|c|}{ Untreated Group } & \multirow[t]{2}{*}{ p-value } \\
\hline & $N=13,407$ & $\%$ & $N=16,204$ & $\%$ & \\
\hline Age, mean (SD), years & 70.9927 & 9.441 & 67.0571 & 12.057 & $<0.0001$ \\
\hline $\begin{array}{l}\text { Age group } \\
40 \leq \text { age } \leq 54 \\
55 \leq \text { age } \leq 64 \\
65 \leq \text { age } \leq 74 \\
75 \leq \text { age }\end{array}$ & $\begin{array}{r}849 \\
2134 \\
5213 \\
5211\end{array}$ & $\begin{array}{r}6.33 \\
15.92 \\
38.88 \\
38.87\end{array}$ & $\begin{array}{l}3010 \\
3241 \\
4836 \\
5117\end{array}$ & $\begin{array}{r}18.58 \\
20 \\
29.84 \\
31.58\end{array}$ & $<0.0001$ \\
\hline $\begin{array}{l}\text { Sex } \\
\text { Male } \\
\text { Female }\end{array}$ & $\begin{array}{l}4271 \\
9136\end{array}$ & $\begin{array}{l}31.86 \\
68.14\end{array}$ & $\begin{array}{l}9459 \\
6745\end{array}$ & $\begin{array}{l}58.37 \\
41.63\end{array}$ & $<0.0001$ \\
\hline $\begin{array}{l}\text { Urbanization level } \\
\text { Urban } \\
\text { Suburban } \\
\text { Rural }\end{array}$ & $\begin{array}{l}6088 \\
5586 \\
1733\end{array}$ & $\begin{array}{l}45.41 \\
41.66 \\
12.93\end{array}$ & $\begin{array}{l}7629 \\
6466 \\
2109\end{array}$ & $\begin{array}{r}47.08 \\
39.9 \\
13.02\end{array}$ & 0.0065 \\
\hline \multicolumn{6}{|l|}{ Comorbidity } \\
\hline Lung cancer & 261 & 1.95 & 754 & 4.65 & $<0.0001$ \\
\hline Dyslipidemia & 3071 & 22.91 & 3752 & 23.15 & 0.6128 \\
\hline Hypertension & 8716 & 65.01 & 9962 & 61.48 & $<0.0001$ \\
\hline Diabetes mellitus & 3492 & 26.05 & 4475 & 27.62 & 0.0024 \\
\hline Obesity & 56 & 0.42 & 66 & 0.41 & 0.8896 \\
\hline Chronic kidney disease & 727 & 5.42 & 1223 & 7.55 & $<0.0001$ \\
\hline Chronic liver disease & 2010 & 14.99 & 2740 & 16.9 & $<0.0001$ \\
\hline Malignancy & 2398 & 17.89 & 3694 & 22.8 & $<0.0001$ \\
\hline Pneumonia & 2095 & 15.63 & 3068 & 18.93 & $<0.0001$ \\
\hline Alcohol-related disease & 55 & 0.41 & 195 & 1.2 & $<0.0001$ \\
\hline Renal failure & 318 & 2.37 & 525 & 3.24 & $<0.0001$ \\
\hline Dementia & 743 & 5.54 & 1133 & 6.99 & $<0.0001$ \\
\hline Alzheimer's disease & 98 & 0.73 & 112 & 0.69 & 0.6848 \\
\hline Depression & 1108 & 8.26 & 1154 & 7.12 & 0.0002 \\
\hline Coronary artery disease & 3809 & 28.41 & 4157 & 25.65 & $<0.0001$ \\
\hline Peripheral vascular disease & 864 & 6.44 & 1032 & 6.37 & 0.7914 \\
\hline Ischemic stroke/Transient ischemic attack & 2226 & 16.6 & 2674 & 16.5 & 0.8156 \\
\hline Hemorrhagic stroke & 186 & 1.39 & 338 & 2.09 & $<0.0001$ \\
\hline Heart failure & 2083 & 15.54 & 2398 & 14.8 & 0.0778 \\
\hline Left ventricular hypertrophy & 180 & 1.34 & 200 & 1.23 & 0.4098 \\
\hline Atrial fibrillation & 1918 & $|4.3|$ & 2118 & 13.07 & 0.002 \\
\hline Cardiovascular disease $^{\mathrm{a}}$ & 6481 & 48.34 & 7388 & 45.59 & $<0.0001$ \\
\hline Steroid use & 4640 & 34.61 & 5518 & 34.05 & 0.3162 \\
\hline Median follow-up duration (days, median) & 28 & & 1496 & & \\
\hline \multicolumn{6}{|l|}{ COPD exacerbations in one year } \\
\hline Moderate exacerbations & & & & & 0.7985 \\
\hline 0 & 12,009 & 89.57 & $|4,52|$ & 89.61 & \\
\hline 1 & 618 & 4.61 & 764 & 4.71 & \\
\hline$\geq 2$ & 780 & 5.82 & 919 & 5.67 & \\
\hline
\end{tabular}

(Continued) 
Table I (Continued).

\begin{tabular}{|c|c|c|c|c|c|}
\hline \multirow[t]{2}{*}{ Baseline Characteristics, n (\%) } & \multicolumn{2}{|c|}{ Treated Group } & \multicolumn{2}{|c|}{ Untreated Group } & \multirow[t]{2}{*}{$p$-value } \\
\hline & $N=13,407$ & $\%$ & $N=16,204$ & $\%$ & \\
\hline Severe exacerbations & & & & & 0.8581 \\
\hline 0 & 11,482 & 85.64 & 13,884 & 85.68 & \\
\hline I & 1260 & 9.4 & 1537 & 9.49 & \\
\hline$\geq 2$ & 665 & 4.96 & 783 & 4.83 & \\
\hline \multicolumn{6}{|l|}{ Medication for COPD } \\
\hline LABA & 407 & 3.04 & 434 & 2.68 & 0.0654 \\
\hline LABA/ICS & 1399 & 10.43 & 1500 & 9.26 & 0.0007 \\
\hline LAMA & 603 & 4.5 & 679 & 4.19 & 0.1959 \\
\hline LABA/LAMA & 46 & 0.34 & 76 & 0.47 & 0.0564 \\
\hline SABA & 2356 & 17.57 & 2770 & 17.09 & 0.2788 \\
\hline SAMA & 1362 & 10.16 & 1661 & 10.25 & 0.7953 \\
\hline Systemic $\beta 2$ agonists & 6033 & 45 & 6890 & 42.52 & $<0.0001$ \\
\hline ICS & 426 & 3.18 & 405 & 2.5 & 0.0004 \\
\hline Corticosteroid & 7160 & 53.4 & 8224 & 50.75 & $<0.0001$ \\
\hline Methyl-xanthines & 7601 & 56.69 & 8547 & 52.75 & $<0.0001$ \\
\hline Antibiotics & 7426 & 55.39 & 9106 & 56.2 & 0.1639 \\
\hline
\end{tabular}

Note: ${ }^{a}$ Cardiovascular disease included coronary artery disease, peripheral vascular disease, ischemic stroke (transient ischemic attack), hemorrhagic stroke, or heart failure.

Abbreviations: LABA, long-acting $\beta 2$ agonists; ICS, inhaled corticosteroids; LAMA, long acting muscarinic antagonist; SABA, short-acting $\beta 2$ agonists; SAMA, short-acting muscarinic antagonist.

vascular disease, ischemic stroke, hemorrhagic stroke, or heart failure), diabetes and dyslipidemia. A total of 53.4\% of the patients had been prescribed steroids least once within the year prior to the diagnosis of osteoporosis. A total of $34.61 \%$ of the patients had received systemic corticosteroids with a daily dose equivalent to $5 \mathrm{mg}$ of prednisolone within the 3 months prior to the diagnosis of osteoporosis. Oral xanthium was used by $56.69 \%$ of the COPD patients with osteoporosis who received treatment. Among the patients with COPD and osteoporosis who received treatment, $4.61 \%$ had one moderate COPD exacerbation, and $5.82 \%$ had $\geq 2$ moderate exacerbations, 9.4\% had one severe COPD exacerbation, and $4.96 \%$ had $\geq 2$ severe exacerbations.

Among the patients who did not receive treatment, the majority were male $(\mathrm{n}=9459)$, accounting for $58.37 \%$ of all treated patients. The age distribution across age groups with 15 -year intervals was as follows: $18.58 \%$ (3010) of the patients were $40-54$ years old, $20 \%$ (3241) were 55-64 years old, 29.84\% (4836) were 65-74 years old, and $31.58 \%$ (5117) were 75 years old or older.
The average length of follow-up was 28 days from the diagnosis of COPD to the diagnosis of osteoporosis.

Table 1. Characteristics of COPD patients with osteoporosis who did and did not receive treatment.

Table 2 shows the prescription pattern in COPD patients with osteoporosis who received treatment. The most common type of medication for osteoporosis was bisphosphonates, including alendronate, risedronate, ibandronate, and zoledronate, which were used by $36.1 \%$, $0.13 \%, 2.51 \%$, and $6.33 \%$ of the treated patients, respectively.

The second and third most common types of medication used to treat osteoporosis were PTH (1-34) and calcitonin, which were used by $3.21 \%$ and $13.44 \%$ of all treated patients, respectively.

Table 3 shows the HRs for the prescription of drugs after the diagnosis of osteoporosis. Females had a higher probability than males of being prescribed medication for osteoporosis, with an adjusted HR of 1.577 (95\% CI: 1.487-1.672). The older the patient was, the higher the probability of the prescription of medication for osteo- 
Table 2 COPD Patients with Osteoporosis Who Received Treatment Within One Year

\begin{tabular}{|c|c|c|c|c|}
\hline & \multicolumn{2}{|c|}{$\begin{array}{c}\text { Patients Who } \\
\text { Received } \\
\text { Treatment }\end{array}$} & \multirow{2}{*}{$\begin{array}{l}\begin{array}{c}\text { Time from } \\
\text { Diagnosis } \\
\text { to } \\
\text { Treatment }\end{array} \\
\text { (Mean) } \\
\text { (Days) }\end{array}$} & \multirow{2}{*}{$\begin{array}{r}\begin{array}{r}\text { Time from } \\
\text { Diagnosis } \\
\text { to } \\
\text { Treatment }\end{array} \\
\begin{array}{r}\text { (Median) } \\
\text { (Days) }\end{array}\end{array}$} \\
\hline & $N=13,407$ & $\%$ & & \\
\hline \multicolumn{5}{|c|}{ Bisphosphonates } \\
\hline Alendronate & 4840 & 36.1 & 380.81 & 28 \\
\hline Risedronate & 17 & 0.13 & 1157.18 & 304 \\
\hline lbandronate & 337 & 2.51 & 904.10 & 149 \\
\hline Zoledronate & 849 & 6.33 & 535.49 & 51 \\
\hline \multicolumn{5}{|c|}{ Monoclonal antibodies } \\
\hline Denosumab & 1135 & 8.47 & 894.71 & 179 \\
\hline \multicolumn{5}{|c|}{ Hormone-related therapies } \\
\hline Estrogen & 825 & 6.15 & 621.78 & 332 \\
\hline Raloxifene & 1306 & 9.74 & 471.24 & 29 \\
\hline $\begin{array}{l}\text { Parathyroid } \\
\text { hormone } \\
(1-34)\end{array}$ & 431 & 3.21 & 504.89 & 38 \\
\hline $\begin{array}{l}\text { Calcitonin } \\
\text { injection }\end{array}$ & 1802 & 13.44 & 291.77 & 3 \\
\hline $\begin{array}{l}\text { Calcitonin } \\
\text { nasal spray }\end{array}$ & 2249 & 16.77 & 266.97 & 10 \\
\hline
\end{tabular}

porosis. Patients with depression had a relatively high probability of receiving medication for osteoporosis.

\section{Discussion}

Our study showed that patients with COPD and osteoporosis were undertreated. Female patients had a higher probability than males of receiving treatment. Patients with COPD had multiple comorbidities, and osteoporosis was one of the most common comorbidities. ${ }^{11}$ COPD patients were more susceptible to bone fractures and osteoporosis than non-COPD patients after controlling for age and sex. ${ }^{12}$ Fractures can lead to further pulmonary function deterioration and impair daily activities and quality of life in COPD patients. Thus, COPD and fractures form a vicious cycle, imposing a significant burden on these patients. ${ }^{13}$ In addition, fractures also increase the risk of mortality in COPD patients.

Yamauchi et $\mathrm{al}^{14}$ used a Japanese database to study the association between in-hospital mortality and bone fractures in COPD patients and found that patients with hip fractures were older, had a lower body mass index and had a worse general condition than those with vertebral, shoulder, or forearm fractures, and the in-hospital mortality rates in those patients were $7.4 \%, 5.2 \%, 3.9 \%$, and $1.3 \%$, respectively. The rate of mortality following hip fracture in COPD patients was also higher than that in patients without COPD. COPD increased the risk of mortality 1.6 times and 1.7 times at 3 months and 1 year after a hip fracture, respectively. ${ }^{5}$ However, in our study, we found that less than $50 \%$ of the patients with COPD and osteoporosis received treatment. Most osteoporosis patients are undertreated. Osteoporosis is severely undertreated in COPD patients. ${ }^{10,14-16}$

Two articles very briefly addressed the treatment of osteoporosis in patients with COPD. Graat-Verboom et $\mathrm{al}^{10}$ found that only $18 \%$ of the patients with COPD were treated with medications related to skeletal disorders, $23 \%$ of the patients with osteopenia were prescribed medications, and only $8.1 \%$ of the patients with COPD received medications related to skeletal disorders. Univariate analyses showed that patients with COPD who were not treated for osteoporosis had a three-fold higher risk of being diagnosed with osteoporosis between the ages of 55-65 years and a 4.5 -fold higher risk after the age of 65 years. The risk of osteopenia was three times higher in patients older than 65 years. There is a rational explanation for the link between these two conditions, especially if systemic inflammatory issues are taken into consideration. ${ }^{10}$ Additionally, both conditions have interconnected overlapping characteristics and might share some clinical features. ${ }^{17,18}$

There are some possible reasons for the low percentage of COPD patients who received treatment for osteoporosis. First, physicians may neglect the importance of treatment for osteoporosis, and complications of osteoporosis are also ignored. Second, the rapid expansion of medical knowledge and technology promotes medical specialization. Trends toward specialization have increased concerns about the focused treatment of specific diseases to the detriment of systemic evaluations. ${ }^{11}$ Many physicians are encouraged to specialize, and pulmonologists may concentrate on only respiratory diseases. This specialization may result in fragmented care and inefficient referrals to other specialists, resulting in the neglect of other diseases. ${ }^{19}$ Pulmonologists may focus on COPD and neglect osteoporosis. Third, patients with COPD are older and may have dementia, which is often accompanied by a sedentary lifestyle, and physicians may believe that treatment for osteoporosis is not necessary. Fourth, patients with COPD without symptoms of osteoporosis 
Table 3 Hazard Ratios for the Prescription of Drugs After Osteoporosis

\begin{tabular}{|c|c|c|c|c|c|c|c|c|c|}
\hline & \multirow[t]{2}{*}{$\mathbf{N}$} & \multirow[t]{2}{*}{ Crude HR } & \multicolumn{2}{|r|}{$95 \% \mathrm{Cl}$} & \multirow[t]{2}{*}{$p$ value } & \multirow[t]{2}{*}{ Adjusted HR } & \multicolumn{2}{|r|}{$95 \% \mathrm{Cl}$} & \multirow[t]{2}{*}{$p$ value } \\
\hline & & & Lower & Upper & & & Lower & Upper & \\
\hline \multicolumn{10}{|l|}{ Sex } \\
\hline Male & 13,730 & & & & Reference & \multicolumn{4}{|r|}{ Reference } \\
\hline Female & $|5,88|$ & 1.582 & 1.493 & 1.676 & $<0.0001$ & 1.577 & 1.487 & 1.672 & $<0.0001$ \\
\hline \multicolumn{10}{|l|}{ Age (years) } \\
\hline $40 \leq$ age $\leq 54$ & 3859 & \multicolumn{4}{|r|}{ Reference } & \multicolumn{4}{|r|}{ Reference } \\
\hline $55 \leq$ age $\leq 64$ & 5375 & 2.135 & 1.848 & 2.465 & $<0.0001$ & 1.998 & 1.844 & 2.165 & $<0.0001$ \\
\hline $65 \leq$ age $\leq 74$ & 10,049 & 3.14 & 2.752 & 3.582 & $<0.0001$ & 2.817 & 2.577 & 3.079 & $<0.0001$ \\
\hline $75 \leq$ age & 10,328 & 3.849 & 3.377 & 4.387 & $<0.0001$ & 3.429 & 3.179 & 3.699 & $<0.0001$ \\
\hline \multicolumn{10}{|l|}{ Comorbidities } \\
\hline Alcohol-related disease & 250 & 0.408 & 0.313 & 0.532 & $<0.0001$ & 0.905 & 0.693 & 1.183 & 0.4667 \\
\hline Cardiovascular disease & 13,869 & 1.156 & 1.118 & 1.196 & $<0.0001$ & 1.031 & 0.995 & 1.069 & 0.0896 \\
\hline Chronic kidney disease & 1950 & 0.771 & 0.681 & 0.872 & $<0.0001$ & 0.793 & 0.699 & 0.899 & 0.0003 \\
\hline Liver disease & 4750 & 0.791 & 0.73 & 0.857 & $<0.000$ I & 0.926 & 0.854 & 1.004 & 0.0616 \\
\hline Diabetes & 7967 & 0.991 & 0.954 & 1.03 & 0.6531 & 0.953 & 0.915 & 0.992 & 0.019 \\
\hline Dyslipidemia & 6823 & 0.965 & 0.927 & 1.004 & 0.0807 & 0.953 & 0.914 & 0.995 & 0.0269 \\
\hline Hypertension & 18,678 & 1.174 & 1.133 & 1.217 & $<0.0001$ & 1.007 & 0.97 & 1.046 & 0.7017 \\
\hline Dementia & 1876 & 1.037 & 1.008 & 1.067 & 0.013 & 0.932 & 0.833 & 1.043 & 0.2227 \\
\hline Depression & 2262 & 1.117 & 1.05 & 1.187 & 0.0004 & 1.141 & 1.072 & 1.214 & $<0.0001$ \\
\hline Alzheimer's disease & 210 & 1.143 & 0.937 & 1.394 & 0.1887 & 1.061 & 0.866 & 1.3 & 0.565 \\
\hline Renal failure & 843 & 0.869 & 0.777 & 0.971 & 0.0132 & 0.918 & 0.819 & 1.03 & 0.1444 \\
\hline Malignancy & 6092 & 0.953 & 0.938 & 0.969 & $<0.0001$ & 0.893 & 0.83 & 0.961 & 0.0024 \\
\hline \multicolumn{10}{|l|}{ Medication } \\
\hline Steroid use & 10,158 & 1.076 & 1.038 & 1.115 & $<0.0001$ & 1.126 & 1.087 & 1.167 & $<0.0001$ \\
\hline Estrogen use & 825 & 2.76 & 2.572 & 2.962 & $<0.0001$ & 0.714 & 0.603 & 0.844 & $<0.0001$ \\
\hline \multicolumn{10}{|l|}{ Urbanization status } \\
\hline Urban & 13,717 & & & & Reference & & & & Reference \\
\hline Suburban & 12,052 & 1.069 & 1.031 & 1.108 & 0.0003 & 1.016 & 0.98 & 1.054 & 0.2879 \\
\hline Rural & 3842 & 1.034 & 0.98 & 1.09 & 0.225 & 0.954 & 0.904 & 1.006 & 0.077 \\
\hline
\end{tabular}

Abbreviations: $\mathrm{Cl}$, confidence interval; $\mathrm{HR}$, hazard ratio.

may not receive treatment for osteoporosis. In addition, patients with COPD and multiple comorbidities may refuse treatment due to the greater number of different medicines prescribed and the higher dosing frequency.

COPD can be associated with commodities that have systemic implications affecting not only the respiratory system but also other major organ systems. Osteoporosis is highly prevalent among patients with COPD. However, the specific pathophysiological interaction between the two conditions is still unclear. Physicians may fail to recognize the importance of prompt interventions. There is an urgent need for more timely treatment of osteoporosis in patients with COPD.

There are some limitations of this study. Our data only included patients who had been diagnosed with osteoporosis, and our data did not include laboratory data, such as pulmonary function tests and bone density measurements. Therefore, we did not have metrics of disease severity. However, we identified osteoporotic patients based on physician diagnoses, and the diagnoses were reviewed by experts; therefore, the accuracy of the diagnoses was improved. Coding errors are a problem 
when using a database. We enrolled patients who had records of the diagnosis of COPD and the prescription of bronchodilators. The prevalence of co-morbidities alone should prompt clinicians to think about bone densitometry assessment. In our study, we do not know how many individuals with COPD actually had some form of bone densitometry assessment and how often it was performed which is likely to influence the findings. The strengths of our study is that the NHIRD includes more than $99 \%$ of the population in Taiwan, and we comprehensively enrolled the eligible subjects. Thus, this populationbased study with a long follow-up duration is representative of the Taiwanese population, avoiding selection bias.

\section{Conclusion}

Osteoporosis is highly prevalent and undertreated in patients with COPD. It is reasonable to implement osteoporosis screening programs and promote aggressive treatment of osteoporosis in patients with COPD. The undertreatment of osteoporosis in patients with COPD seems to be a weakness of the health-care system and could be improved by aggressive and timely treatment. In our study, we found that female patients received treatment more often and treatment increases considerably with age. Treatment should pay more attention to male patients and young population.

\section{Abbreviations}

$\mathrm{CI}$, confidence interval; COPD, chronic obstructive pulmonary disease; HR, hazard ration; LABA+ICS, longacting $\beta 2$-agonists and inhaled corticosteroids; LABA, long-acting $\beta 2$-agonists, LAMA, long-acting muscarinic antagonists; SABA, short-acting $\beta 2$-agonists; SAMA, short-acting muscarinic antagonists.

\section{Acknowledgments}

This study was based in part on data from the NHIRD provided by the Bureau of National Health Insurance (BNHI) of the Ministry of Health and Welfare. The conclusions presented in this study are those of the authors and do not necessarily reflect the views of the BNHI, the Ministry of Health and Welfare. We thank the Center for Medical Informatics and Statistics of Kaohsiung Medical University for providing administrative and funding support.

\section{Funding}

This work was supported by a grant from the Chi Mei Medical Center, Chali, Taiwan. (CCFHR10902).

\section{Disclosure}

The authors declare no conflicts of interest in association with the present study. The abstract has been presented at the 2020 Annual Congress of Taiwan Society of Pulmonary and Critical Care Medicine, Taiwan Society of Thoracic Surgeons, and Taiwan Association of Thoracic \& Cardiovascular Surgery Joint Conference.

\section{References}

1. Andreassen H, Vestbo J. Chronic obstructive pulmonary disease as a systemic disease: an epidemiological perspective. Eur Respir J Suppl. 2003;46:2s-4s. doi:10.1183/09031936.03.00000203

2. Bolton CE, Ionescu AA, Shiels KM, et al. Associated loss of fat-free mass and bone mineral density in chronic obstructive pulmonary disease. Am J Respir Crit Care Med. 2004;170:1286-1293. doi:10.1164/rccm.200406-754OC

3. Decramer M, Janssens W, Miravitlles M. Chronic obstructive pulmonary disease. Lancet. 2012;379(9823):1341-1351. doi:10.1016/ S0140-6736(11)60968-9

4. Cielen N, Maes K, Gayan-Ramirez G. Musculoskeletal disorders in chronic obstructive pulmonary disease. Biomed Res Int. 2014;2014:965764. doi:10.1155/2014/965764

5. Inoue D, Watanabe R, Okazaki R. COPD and osteoporosis: links, risks, and treatment challenges. Int J Chron Obstruct Pulmon Dis. 2016;11:637-648. doi:10.2147/COPD.S79638

6. Akyea RK, McKeever TM, Gibson J, Scullion JE, Bolton CE. Predicting fracture risk in patients with chronic obstructive pulmonary disease: a UK-based population-based cohort study. BMJ Open. 2019;9:e024951. doi:10.1136/bmjopen-2018-024951

7. de Luise C, Brimacombe M, Pedersen L. Chronic obstructive pulmonary disease and mortality following hip fracture: a population-based cohort study. Eur J Epidemiol. 2008;23:115. doi:10.1007/s10654-007-9211-5

8. Bilezikian MD. Efficacy of bisphosphonates in reducing fracture risk in postmenopausal osteoporosis. Am J Med. 2009;122(2):S14-S21. doi:10.1016/j.amjmed.2008.12.003

9. Cesareo R, Lozzino M, D'onofrio L. Effectiveness and safety of calcium and vitamin D treatment for postmenopausal osteoporosis. Minerva Endocrinol. 2015;40(3):231-237.

10. Graat-Verboom L, Spruit MA, van den Borne BEEM, et al. Correlates of osteoporosis in chronic obstructive pulmonary disease: an underestimated systemic component. Respir Med. 2009;103:1143-1151. doi:10.1016/j.rmed.2009.02.014

11. Ferguson GT, Calverley PMA, Anderson JA, et al. Prevalence and progression of osteoporosis in patients with COPD. Chest. 2009;136:1456-1465. doi:10.1378/chest.08-3016

12. Brask-Lindemann D, Eiken P, Eskildsen P, Abrahamsen B. Time trends for alendronate prescription practices in women with chronic obstructive pulmonary disease and women exposed to systemic glucocorticoids. Osteoporos Int. 2013;24(6):1891-1897. doi:10.1007/s00198-012-2220-6

13. Graat-Verboom L, van den Borne BE, Smeenk FW, Spruit MA, Wouters EF. Osteoporosis in COPD outpatients based on bone mineral density and vertebral fractures. J Bone Miner Res. 2011;26 (3):561-568. doi:10.1002/jbmr.257 
14. Yamauchi Y, Yasunaga H, Sakamoto Y, et al. Mortality associated with bone fractures in COPD patients. Int J Chron Obstruct Pulmon Dis. 2016;11:2335-2340. doi:10.2147/COPD.S112142

15. Cha YH, Ha YC, Park HJ, et al. Relationship of chronic obstructive pulmonary disease severity with early and late mortality in elderly patients with hip fracture. Injury. 2019;50(9):1529-1533. doi:10.1016/j.injury.2019.05.021

16. Watanabe R, Tanaka T, Aita K, et al. Osteoporosis is highly prevalent in Japanese males with chronic obstructive pulmonary disease and is associated with deteriorated pulmonary function. $J$ Bone Miner Metab. 2015;33(4):392-400. doi:10.1007/s00774-014-0605-7
17. Carter JD, Patel S, Sultan FL, et al. The recognition and treatment of vertebral fractures in males with chronic obstructive pulmonary disease. Respir Med. 2008;102(8):1165-1172. doi:10.1016/j. rmed.2008.03.003

18. Majumdar SR, Villa-Roel C, Lyons KJ, Rowe BH. Prevalence and predictors of vertebral fracture in patients with chronic obstructive pulmonary disease. Respir Med. 2010;104(2):260-266. doi:10.1016/j. rmed.2009.09.013

19. Green AR, Carrillo JE, Betancourt JR. Why the disease-based model of medicine fails our patients. West J Med. 2002;176(2):141-143.

\section{Publish your work in this journal}

The International Journal of COPD is an international, peer-reviewed journal of therapeutics and pharmacology focusing on concise rapid reporting of clinical studies and reviews in COPD. Special focus is given to the pathophysiological processes underlying the disease, intervention programs, patient focused education, and self management protocols. This journal is indexed on PubMed Central, MedLine and CAS. The manuscript management system is completely online and includes a very quick and fair peer-review system, which is all easy to use. Visit http://www.dovepress.com/testimonials.php to read real quotes from published authors.

Submit your manuscript here: https://www.dovepress.com/international-journal-of-chronic-obstructive-pulmonary-disease-journal 